\title{
INTRANASAL RHINO-DACRYO-CYSTOSTOMY FOR PERSISTENT EPIPHORA IN CHILDHOOD*
}

BY

\author{
H. S. SHARP
}

London

THE problem of the persistently watering eye in childhood presents different aspects from the similar condition in later life. The watering seems to worry the child most of the time and not to be confined to stimulus by cold air as. is often the case in adults. Infection is prone to occur and is difficult to control. The small size of the lacrimal apparatus makes probing difficult, and necessitates general anaesthesia on each occasion.

No attempt will be made in this annotation to discuss the aetiology or pathology of this condition: the intention is simply to describe a procedure which has been found useful.

Probing and dilatation by the ophthalmologist will result in a cure in the majority of cases, but occasionally repeated probing and dilatation fail to result in a satisfactory outcome. It is in these cases that a further procedure is necessary.

It appeared to me that the usual operation of the external approach to the lacrimal apparatus, such as is used in later life, was less acceptable in young children, since a scar on the developing face, however inconspicuous, is to be avoided if possible. Consequently I decided to employ the intranasal approach.

There is nothing original in the concept of the intranasal approach to the lacrimal sac; it has been described for many years, but there are some modifications of technique which $I$ have used for these children. The operation is not difficult in spite of the smallness of the nose in childhood.

\section{Coperative Technique}

Half an hour before operation the affected side of the child's nose is packed with ribbon gauze which has been wrung out in a solution of 10 per cent. cocaine and $1: 1,000$ adrenaline, equal parts. General anaesthesia is used, with an intra-tracheal tube, around which is a pack to prevent any secretion entering the bronchial tree.

An expanding Killian speculum is inserted into the nostril on the affected side, and opened as wide as possible, and the pack, which was placed in situ before the anaesthetic, removed. 2 minims $1: 1,000$ adrenaline in $0.5 \mathrm{ml}$. normal saline is then injected under the muco-periosteum in the area immediately anterior to the middle turbinal. A quadrilateral piece of muco-periosteum is then cut out and removed completely in the area shown in the diagram, using a small knife. There is no possibility of performing any intranasal suturing of the nasal muco-periosteum to the lacrimal sac in the small area of a child's nose, but it is very important that

*Received for publication December 2, 1953. 
the muco-periosteal square be completely removed, leaving bare bone underneath. This bone is now removed, using at first a curved gouge for the initial cut, and after that, punch forceps, so that all bone corresponding to the muco-periosteal square, is removed.

A probe is then passed through the canaliculus of the lower lid and into the lac-

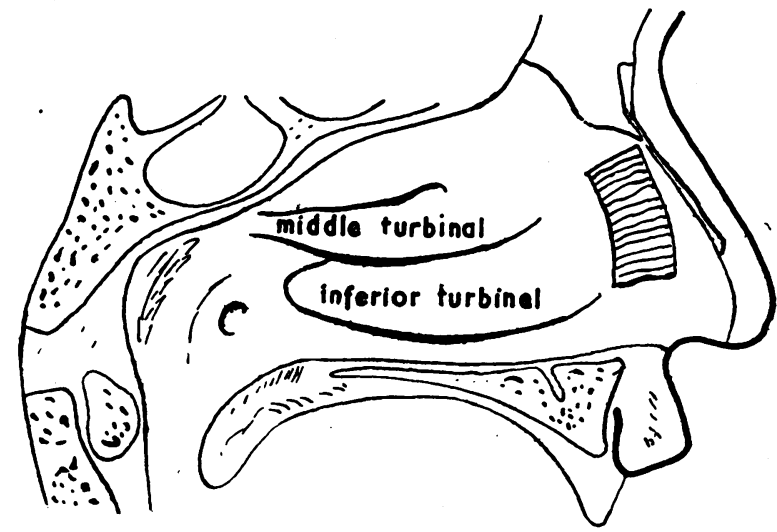

Figure.-The portion of muco-periosteum and underlying bone to be removed is shown by the shaded area. rimal sac, which is dislocated as far as possible into the nose through the newlyfashioned hole. As much as possible of the internal wall of the lacrimal sac is then cut away, using small curved scissors, so that a wide channel is formed, bounded on the outer aspect by the lateral wall of the sac, and leading into the nose through the opening already made in front of the anterior end of the middle turbinal. A pack of ribbon gauze is then placed in the nostril, and this is removed after 12 hours.

Syringing from the canaliculus to the nose is performed on the day following operation, and repeated daily for a week. No further treatment is needed.

Recently a follow up was conducted on seven cases which had undergone intranasal rhino-dacryo-cystostomy during the years 1949-1951. All the cases had dry eyes, and none of the ostia had closed. The patients' ages varied from 3 to 8 years, and all had had repeated probing and dilatation under general anaesthesia before the rhino-dacryo-cystostomy.

I am grateful to my colleague, Mr. J. H. Doggart, for referring these cases to me. 